\title{
PARODIA Y DEPORTE EN QUO VADIS, SÀNCHEZ?, DE FRANCESC TRABAL
}

\section{PARODY AND SPORT IN QUO VADIS, SÀNCHEZ? BY FRANCESC TRABAL}

\author{
Moisés Llopis i Alarcón \\ Pontificia Universidad Católica de Chile, Chile \\ moisesllopis@gmail.com
}

\begin{abstract}
Resumen:
El presente artículo tiene como objetivo estudiar la importancia de la parodia en Francesc Trabal a través del análisis de la novela Quo vadis Sànchez?, publicada en 1931. En primer lugar, se revisan las diferentes consideraciones que ha tenido la obra narrativa del autor por parte de la bibliografía precedente y, más adelante, se destaca la parodia como uno de los aspectos más relevantes que cabe considerar. Posteriormente, se describe el concepto de parodia y se analiza su efectividad en la novela trabaliana. Este análisis de la parodia en la novela de Trabal permite ver el juego de distanciamiento irónico de Trabal contra el modelo y los valores promovidos por la novela deportiva de la época.
\end{abstract}

Palabras clave: parodia, novela deportiva, Francesc Trabal, literatura catalana, ironía intertextual

\begin{abstract}
:
The paper aims to study the importance of parody in Francesc Trabal through the analysis of the novel Quo Vadis, Sànchez?, published in 1931. Firstly, we examine the different considerations about the narrative work of the author shown in previous studies and, later, we underline parody as one of the most relevant aspects for examination. Subsequently, we describe the concept of parody and then we analyse its efficacy in this novel. The analysis of parody lets us understand Trabal's game of ironic distance against the model and the values promoted by the sport novel from the period.
\end{abstract}

Keywords: parody, sport novel, Francesc Trabal, Catalan literature, intertextual irony. 


\section{Introducción}

La lectura de la obra narrativa del escritor catalán Francesc Trabal (Sabadell, 1899 Santiago de Chile, 1957) ha tenido variadas interpretaciones desde que, a finales de los años treinta, las consecuencias políticas y sociales derivadas de la guerra civil española y la victoria franquista provocaron la disolución -física, pero también moral- del conocido como Grup de Sabadell, así como de todo el circuito literario catalán tal como era conocido hasta entonces. En la postguerra, la recepción de la obra de Trabal dejó de tener una interpretación tan entusiasta y, por el contrario, llevó a algunas personalidades reconocidas dentro del panorama crítico - incluyendo antiguos compañeros, como es el caso del también escritor Joan Oliver (Pere Quart) - a leer la propuesta de Trabal con un sentimiento de irritación que la situaba en la línea del humor gratuito y arbitrario, «deliberadament absurd» (Oliver 9).

La comunidad científica recuperó el interés por la obra de Trabal durante la década de los setenta, gracias a las aportaciones en artículos y estudios al entorno de su poética, y del contexto histórico y social dentro del cual se desarrolló, hasta el punto de definir a Trabal como «el novel·lista més innovador de la seva generació, l'únic que havia sabut aportar uns aires nous a la novel-la catalana» (Arnau 120). Sin embargo, a pesar que, de una manera $\mathrm{u}$ otra, todos los estudios han destacado el humor y la ironía como características definitorias (Oller; Pinell; Arnau; Bach; Martí-Olivella; Rosselló i Bover; Dasca; Iribarreny Marrugat), muy a menudo no se han marcado los límites que separan ambos fenómenos, un hecho que ha provocado una confusión interpretativa; o han relacionado humor e ironía con comicidad, con lo cual se ha leído erróneamente la obra de Trabal desde el punto de vista del despropósito, del absurdo.

Josep Maria Balaguer fue el primero en definir la concepción novelística del autor hacia un «determinat tipus d'humor paròdic» (Balaguer, Francesc Trabal i la paròdia 69) que más adelante se concreta en «allò que modernament coneixerem com a "novel·la autoreflexiva" (Balaguer, Francesc Trabal i la paròdia 84). Este fenómeno, además, hace posible la presencia de «una ficció i d'una organització artificiosa de la realitat del llenguatge» (Balaguer, Francesc Trabal i la paròdia 85). Vicent Simbor estudia la parodia como uno de los aspectos básicos de la aportación trabaliana, relacionada con la 
metaficción, y la define a partir de un «joc lúdic amb les convencions novel-lístiques arrelades amb el Realisme i Naturalisme fins a somoure, dislocar, el relat i oferir-ne una alternativa nova i no "realista"» (Simbor 250).El presente artículo pretende ahondar en otra de las estrategias paródicas usadas por Trabal: la que permite leer Quo vadis, Sànchez? como una parodia de la novela deportiva.

\section{El concepto de parodia desde la perspectiva irónica}

El tratamiento de la parodia, procedimiento de un componente estructural irónico considerable, no ha alcanzado todavía un consenso generalizado, a pesar de las diferentes aportaciones de los investigadores. La multiplicidad de opiniones ha provocado que, actualmente, el concepto de parodia haya perdido la concreción significativa con la que fue expresada en el momento de su aparición y se confunda con otros conceptos como el pastiche, el plagio o la sátira. Para acotar y precisar el significado de un concepto tan polisémico como el de la parodia contamos con las contribuciones de las escuelas teóricas francesa y anglosajona que, aunque no son las únicas, es cierto que han contado con una mayor difusión. En el primer caso, hemos de considerar la propuesta que desarrolla Gérard Genette en su volumen Palimpsestes. La littérature au second degré (1992 [1982]), quien identifica la parodia como una de las seis prácticas hipertextuales clasificadas a partir de dos conceptos clave: la relación y el régimen. Esta combinación, estructural y funcional, permite fijar una distinción doble: por una parte, la distinción entre los hipertextos producidos por transformación y los producidos por imitación. Por otra, permite diferenciar los hipertextos según el predominio del régimen lúdico, satírico o serio. La combinación de ambas categorías da lugar a las seis prácticas posibles: parodia o transformación lúdica, travestissement o transformación satírica, transposición o transformación seria, pastiche o imitación lúdica, charge o imitación satírica y forgerie o imitación seria (Genette 33-40). La diferencia general entre cada una es que, mientras las tres primeras (transformación) actúan sobre una obra concreta y, de manera accesoria, sobre un estilo, las tres últimas (imitación) actúan esencialmente sobre un estilo y, accesoriamente, sobre una obra (Genette 89). Así pues, mientras que el pastiche solamente puede referirse al género, la parodia solamente resulta operativa en un texto. Por otra parte, la aportación de Daniel Sangsue respeta la división estructural genettiana entre transformación e imitación (por lo que 
también respeta la concepción misma de los términos de parodia y pastiche) pero, sin embargo, prescinde de la triple división entre regímenes, de manera que entiende la parodia, más ampliamente, como «la transformation ludique, comique ou satirique d'un texte singulier» (Sangsue 73-74).

Sin embargo, la propuesta genettiana ha sido discutida por investigadoras anglosajonas como Margaret A. Rose o Linda Hutcheon, quienes no comparten esta división entre transformación e imitación, de manera que, en rasgos generales, definen la parodia como un hipertexto fruto de un hipotexto anterior entendido no solamente como una obra completa sino como un género, una escuela, un movimiento, un estilo, un período, etc. Así pues, Hutcheon (A Theory 6) la define como «a form of imitation, but imitation characterized by ironic inversion, not always at the expense of the parodied text [...]. Parody is, in another formulation, repetition with critical distance, which marks difference rather than similarity». La diferencia entre ambas tiene que ver con el carácter cómico o no de la parodia. Para Hutcheon, la parodia tiene un componente estructuralmente irónico ( $A$ Theory 54) pero no necesariamente cómico mientras que para Rose la parodia un componente humorístico o cómico (Rose 90-91). Para el análisis de Quo vadis, Sànchez?, seguiremos la propuesta de Linda Hutcheon, de manera que entenderemos la novela de Trabal como una relación intertextual paródica de la novela deportiva.

\section{Quo vadis, Sànchez?o la parodia de la novela deportiva}

En diciembre de 1930, gracias al semanario catalán Mirador, sabemos que el primer Premio Cèsar August Torres destinado a una novela deportiva, se ha declarado desierto. Los motivos de esta decisión, según recoge el articulista, tenían relación o bien con las condiciones novelísticas de las obras presentadas o bien porque no enaltecían el deporte «d'una manera prou satisfactòria». El periodista añadía: «no és cap secret per ningú que l'obra que no enaltia l'esport — Quo vadis, Sànchez? — era de Francesc Trabal. Sembla que el protagonista arribava a campió mundial de baldufa, cosa poc seriosa»; el reportero incluso no podía evitar dudar si jugar a la trompa era realmente un deporte y, además, apuntaba que «la majoria d'aficionats a aquest esport s'hi dediquen amb escassa ciutadania» (Mirador 1).

Domènec Guansé, reconocido crítico catalán y miembro del jurado del Premio, 
junto con Pompeu Fabra, Carles Sindreu, Enric Guardiola Cardellach y Carles Soldevila, en la reseña que dedicó a Quo vadis, Sànchez?, explicaba la razón fundamental del descarte: «els membres del jurat tingueren la temença que la novel-la de Trabal irrités els esportistes; que posés la literatura enfront de l'esport, cosa que era precisament la contrària que amb el concurs volia provocar-se»(Guansé 7). Para el crítico, la nueva propuesta literaria de Trabal quería ser, en realidad, una «mofa» a los valores promovidos por la actividad física, de manera que la novela se desarrollaba bajo el ideal de hacer creer que todo el mundo es apto para un deporte u otro. Esta, de hecho, parecía ser la razón por la que el destino del protagonista desembocaba en «l'infantívol joc del trompitxol», una justificación que provocó «les aprensions del jurat» (Guansé 7). Sin embargo, Guansé valoraba positivamente la publicación de la novela, al mismo tiempo que alababa las cualidades literarias de Trabal — «unànimement reconegudes»; el crítico veía en la novela «un humor més penetrant» que en las dos obras anteriores, L'home que es va perdre (1929) y Judita (1930); un humor que «esdevé especialment satíric i assoleix virtuts i eficiència social». El éxito de Quo vadis, Sànchez? tenía que ver, pues, con una «mena d'acrobàcia literària que hom segueix alhora amb temor i delícia» (Guansé 7). Sin embargo, Manuel de Montoliu, que ya había mostrado su descontento por Judita, ahora describe Quo vadis, Sànchez? como «una novel·la d'ambient modern que transparenta un fons de realitat moral i psicològica $\mathrm{i}$ un sentit humà que l'eleven a un pla superior al vulgar i superficial d'una enginyosa facècia» (Montoliu 5). En el nuevo personaje trabaliano, Sànchez, Montoliu veía «la visió justa i exacta d'aquesta immensa buidor de la imbecilitat humana, encarnada en tants individus que passen pel nostre costat cada dia i que sols pot sorprendre en llur significació universal un observador armat d'una perforadora ironia» (Montoliu 5).

Ahora bien, desde el primer momento que fue rechazada al premio Cèsar August Torres, los miembros del jurado de aquel momento y también algunos estudiosos que se han dedicado a la novela, han reconocido que Quo vadis, Sànchez? es, en gran medida, una parodia de la novela deportiva (Pinell; Poch; Iribarren; Ardolino). De entrada, el título se puede leer desde esta perspectiva irónica. ${ }^{1}$ En efecto, la referencia de la novela del escritor 
polaco Henryk Sienkiewiecz, Quo vadis? (1913), además de la relación paródica respectiva,

evocava els amfiteatres romans, i amb ells la famosa frase 'panes et circenses': els emperadors, per a obtenir el favor del poble, o almenys per assegurar-se'n la submissió, calia que procuressin que no manqués l'aliment quotidià i la diversió; una diversió que consistia essencialment en els grans espectacles de massa. Aquests espectacles -lluites, molt sovint, cruels- més que elevar el poble a una cultura cívica, l'enfonsaven en la misèria mental, desenvolupant en ells els instints bestials (Pinell 51-52).

Resulta, pues, evidente, que Trabal, con el uso de este referente, también adjudica al argumento de la novela y a la construcción del protagonista una visión del mundo romano antiguo o, más concretamente, la reflexión al entorno de una política orientada a mantener a la sociedad en su nivel cultural más bajo mediante el espectáculo de masas de la época, el deporte, fruto también de las continuas transformaciones de la sociedad de la época, sobre todo por lo que respecta a la aparición de la clase burguesa, la cual es cada vez más consciente del tiempo libre que posee (Poch 61). Hablamos de un período histórico, pues, en el que, por una parte, se produce un aumento en el número de prácticas deportivas, de clubes y de deportistas y, por otra parte, la más alarmante, empieza el crecimiento imparable de seguidores, una masa socialmente aceptada y promovida por el ambiente renovado de las ciudades, sobre todo a través de la construcción de nuevas infraestructuras deportivas (Pujadas y Santacana 167). Se trata, por tanto, de un proceso de transformación de los gustos de la sociedad catalana al respecto, que culminará, además, con la celebración de la Exposición Universal de 1929, lo que implicará la construcción de nuevos espacios deportivos y el desarrollo de un programa de actividades deportivas que, sin embargo, fue reservado a una minoría (Poch 61), un carácter que, poco a poco, irá abandonando hasta convertirse, como hemos dicho, en un espectáculo de masas, muy a menudo animado por el apoyo que le otorgará la prensa del momento con secciones dedicadas al deporte o con cabeceras íntegramente dedicadas a este fenómeno: son los casos, por ejemplo, de revistas como Xut! (1922-1936), La Publicitat (1878-1939), La Nau dels Esports (1929-1930),

versión musical cuatro años más tarde. En el caso de Trabal, sin embargo, hay que atender al sentido paródico de la propuesta, puesto que Sànchez no es consciente de la realidad que vive y privilegia la vocación deportiva como medio de desarrollo de su identidad. 
L'Esport Català (1925-1927) o La Rambla de Catalunya (1930-1932), encargada de la publicación de Quo vadis, Sànchez?, a pesar del rechazo inicial del jurado del premio deportivo.

Las primeras obras literarias del momento que demostraron este fenómeno transformador del deporte lo harán desde un punto de vista humorístico o caricaturizador, destacando los problemas que provocan la profesionalización del deporte, el fanatismo o la inmoralidad. Es el caso, por ejemplo, de las comedias L'honor del barri (1930), Una final de campionat o Pirandó i Moixernó, fanàtics (sin fecha) o El partit del diumenge (1925), las tres obras de Valentí Castanys (la última, escrita conjuntamente con Alfons Roure), principal caricaturista de la revista Xut! y, además, autor de los dibujos que acompañan a la novela de Trabal. A pesar de esta primera objeción a la práctica deportiva, gran parte de la literatura catalana abrazará pronto el hecho deportivo y la inclusión de este fenómeno de masas se convertirá en un símbolo de belleza o de modernidad. Son los casos de la Vida privada (1932) de J. M. de Sagarra, o la trilogía de Carles Soldevila Fanny (1929), Eva (1931) y Valentina (1933), en la que se evidencia la transformación moral de una sociedad moderna, la catalana, pendiente de la forma física y de la higiene personal (Poch 61). Pero, en cambio, todavía es posible encontrar autores que se dedican a resaltar el carácter incívico del deporte, como por ejemplo, la poesía «Del tennis relatiu» dentro de las Sàtires (1927) de Guerau de Liost, un poema en el que el autor presenta una solución ciertamente enojona y poco elegante de unos jugadores de tenis que, torpes para el juego, pierden todas las pelotas:

Cada conill faria de pilota, elàstic, resignat i cabdellat, amb una rialleta, mig ganyota, quan endevinaria que és llençat.

I cada volta que, amb jugada forta, engegaríem la pilota lluny, descabdellant-se i una mica torta, per ella sola ens tornaria al puny (Guerau de Liost 157).

Se trata, como vemos, de una consideración, la del deporte, como práctica incívica o, al menos, alejada de los parámetros que se atribuían a la civilidad, que se extenderá 
desde finales de los años 20 hasta prácticamente el inicio de la guerra civil española. En este sentido, conviene reseñar el comentario sobre el deporte entendido como una práctica física que hace Marià Frena, uno de los dos personajes centrales de Crim (1936), la cuarta novela de Mercè Rodoreda y una parodia de la novela negra, sobre todo si tenemos en cuenta la filiación que algunos estudiosos han querido ver entre este personaje rodorediano y Francesc Trabal (Pessarrodona 109; Porta 267): «[1’esport] és emprat obligatòriament per a l'extermini de les dispositats abdominals en els més famosos i menys afamats instituts de bellesa: facilita la lliure circulació, fa elàstiques les extremitats, aclareix les potències i proporciona salut a dojo...» (Rodoreda 76).

Manuel de Montoliu, ya lo sabemos, en una reseña a la novela de Trabal publicada en La Veu de Catalunya el 6 de abril de 1932, convertida en «un himne a la bellesa d'aquesta novetat literària» (Ardolino 367), ya veía en Quo vadis, Sànchez? «un caràcter de paròdia: paròdia de l'aspecte educatiu de l'esport, d'una banda; i de l'altra, paròdia de la preocupació -que la pedagogia moderna tracta de sistematitzar- de la recerca de la vocació» (Montoliu 5). Como apunta Ardolino, Montoliu apostaba por «una orgia de sinònims [el investigador recoge hasta 23 ejemplos] -que de fet no ho són tant- per estabornir el lector i deixar passar, enmig dels focs d'artifici, l'únic missatge que les coloraines dels vidres de l'ampolla no deixaven translluir» (Ardolino 368), y que hace referencia a las oportunidades del autor para «moralitzar amb caràcter general sobre el cas individual per ell observat» (Montoliu 5). Este planteamiento, que aquí hemos interpretado desde el punto de vista de la parodia, hace ver a Trabal como «una de les més notables visions humorístiques dels aspectes característics del viure modern que s'hagin escrit en la literatura catalana» (Montoliu 5). Si queremos resaltar ahora el elogio de Montoliu al escritor sabadellense es precisamente porque pone el énfasis en este «viure modern» que también debemos tener en cuenta para hablar del deporte. Porque el objeto de la parodia de Trabal no es tanto el deporte sino el uso que hace la sociedad. Sànchez, un personaje inseguro, nervioso, lleno de angustias y contradicciones, se marca el deporte como objeto de su vida a partir de una conferencia deportiva organizada por el Club de fútbol Ch. F. C. (Trabal Quo vadis 70): «Aquell dia en Sànchez no pogué pair aquelles paraules. Com un nus a la seva intel-ligència, no podia lligar els seus interiors discursos. Començava a sentir el valor de la pròpia responsabilitat. Experimentava un malestar moral que 1'anguniejava 
com mai». Por eso, la autoridad moral que Sànchez otorga al conferenciante deportivo, más allá de los principios que rigen su experiencia vital, de su «realitat abominada» (Trabal Quo vadis 16), provocan una inestabilidad que desembocará, finalmente, en la salvación del personaje. Ahora bien, existen dos textos más, previos a la publicación de la novela, que pueden servir de antecedente para entender la postura de Trabal respecto a este tema: por una parte, el artículo "Amb això del Terrassa-Sabadell, sembla que ens els prenguin”, publicado en el Diari de Sabadell del 24 de junio de 1925 y el cuento "La venjança dels "Alumnes de Viladecavalls P.T.", publicado en La Rambla de Catalunya el 28 de abril de 1930. En ambos textos, es posible observar de qué manera Trabal desarrolla el tema de la «parodia esportiva» (Ardolino 377). En el primero, escrito por el Sr. Banyeta, uno de los pseudónimos más productivos de Trabal (Bach 72; Balaguer 8), la crónica de uno de los partidos míticos del momento se convierte en realidad en un relato intencionado del escritor, el cual pretende atribuir al deporte un carácter alejado del de simple práctica deportiva que propiamente cumple; además, el texto resalta que si, como competición se juega para ganar, cuando un equipo gana siempre (como ocurre ahora con el Sabadell, que ha ganado «per mil·lèsima vegada» (Banyeta s.p.) al Terrassa), se pierde el interés, y esto es una muestra de las contradicciones del espíritu humano: «si sabem per endavant que els nostres han de guanyar, ja és allò que s'ho facin, i de deixar-los anar sols, a porta tancada, i guardar la ressenya d'un partit endarrerit per anar-la reproduint indefinidament cada vegada que vagin jugant»(Banyeta s.p.). El objetivo del texto es, pues, pedir que «la Junta del Centre d'Esports se n'empesqui alguna per desvetllar l'afició quan es plantegi una lluita entre aquests dos bàndols» (Banyeta s.p.). El artículo termina con una advertencia que activa el planteamiento irónico de la propuesta, «Perquè, una de tres, que deia aquest dia el meu amic Ribalta, o perden els nostres d'una vegada, o per anar a veure sempre el mateix, no vaig més a futbol!»(Banyeta s.p.). En realidad, poco le importaba a Trabal si el Terrassa ganaba al Sabadell (en la temporada 24-25, el Terressa quedó en mejor posición que el Sabadell (Poch 69)). En realidad, Trabal evidenciaba así el poco interés que el deporte, y más concretamente, el fútbol, despertaba en la sociedad del momento si no se enmarcaba en una competición real que hiciera imprevisible la actividad. Como apunta el propio texto, «tot allò que no guarda una miqueta de misteri, tot allò que en el fons no té l'atzar fent equilibris, acabar per avorrir o per devenir monòton»(Banyeta s.p.). El segundo texto se 
trata de un cuento que narra la historia de un club de fútbol marginado por la Federación Catalana y de la venganza que el equipo perdedor, el Viladecavalls, decide llevar a cabo: una solicitud de conferencia que culturice a los seguidores del campo para evitar los altercados y a la que acude únicamente público con diversidad funcional (personas invidentes, con sordera, con movilidad reducida) e indigentes que han sido contratados por el mismo club. Nuevamente, Trabal utiliza el leitmotiv del deporte para ridiculizarlo; en este caso, para criticar el fanatismo y la veneración que la sociedad profesaba hacia la práctica deportiva y la voluntad de algunas instituciones de convertir el deporte en una tendencia cultural, un hecho que, como ocurre en este relato, choca directamente con el carácter incívico con el que la sociedad lo interpreta (Trabal, La venjança...). Esta mirada tendrá unas implicaciones directas en la construcción de la identidad del individuo, completamente dirigido por estos falsos ideales de civilidad y modernidad, como tendremos ocasión de comprobar en el análisis de la parodia de la novela deportiva planteada por Trabal, Quo vadis, Sànchez?

La novela se inicia con un partido de fútbol a las afueras de Barcelona, instancia que sirve además para conocer al protagonista, mientras sus compañeros le gritan que salga a cubrir la vacante de portero: Sànchez. Es aquí donde sabemos que estamos delante de un personaje poco dotado para la práctica deportiva o, al menos, que no disfruta de un entrenamiento constante, ya que el narrador lo describe como «una mica botarut, sense ésser gras, infladet» (Trabal, Quo vadis 11). Sànchez siente por el fútbol «una marcada predilecció» y, además, ha iniciado «una mena d'amistats» con los socios de un club de tenis, «on no gosava anar sinó els diumenges, que portava el vestit de les festes, duia camisa amb coll tou, i punys» (Trabal,Quo vadis 15). En cualquier caso, el hecho remarcable es el desajuste social que hay entre los socios de este club de tenis y el protagonista. Por eso, cuando está con ellos, el narrador nos aclara que

En Sànchez no ho veia clar. No hi havia manera d'entendre aquella manera de comptar. I sobretot es perdia en els avantatges. Allò sí que era un laberint. Fins al game normal encara hi arribava. Per inèrcia, i seguint una mena de càlcul particular que ni ell sabia com s'havia conjuminat, seguia el fil bastant bé; però quan la partida s'allargava en els avantatges, aleshores era home a l'aigua (Trabal,Quo vadis 39). 
Sànchez, por tanto, no encaja en un juego tan refinado como el tenis y, por más que el señor Saus se lo explique treinta y siete veces, nuestro protagonista se acaba sintiendo «perdut com un canari flauta en una gàbia a ple sol» (Trabal,Quo vadis 39) y se acaba dedicando a lo que realmente sabe hacer: entretener a los socios. Así, Sànchez no es valorado como jugador de tenis sino como «clown improvisat i a la vegada públic» (Trabal,Quo vadis 41), todo lo contrario de lo que pretendía. Por eso, el descubrimiento de los billetes que finalmente lo hace millonario le otorga una estabilidad económica que le ha de permitir convertirse no solamente en un buen futbolista sino también, y sobre todo, en «tot un cavaller» (Trabal,Quo vadis 33), razón por la que comprará una nueva vivienda que adaptará a los gustos de esta vida moderna y se hará poner cuatro dientes de oro, imitando las de Tena, su entrenador personal, un hecho que, como vemos, no le da tampoco el prestigio social que busca.

Sin embargo, y a pesar de este primer fracaso, el enamoramiento de Sànchez lo precipita irremediablemente al boxeo prácticamente sin ninguna preparación física, lo que le provoca una derrota «descomunal, inenarrable» (Trabal,Quo vadis 52) que ya conocemos. En este punto, Anna Poch (65) ve un punto de inflexión por parte del escritor sabadellense: «el món de la boxa, per les seves característiques, no hauria de ser sinònim de vulgaritat sinó que un combat decent, amb boxejadors preparats, hauria d'esdevenir un clar motiu de respecte». En este punto, cabe destacar la similitud de la escena con otro combate señalado por Ardolino (372-373): el que opuso Arthur Cravan al campeón del mundo Jack Johnson el 23 de abril de 191 en la Monumental de Barcelona, y que fue recogido por la prensa de la época con descripciones que caricaturizaban al primer participante. Destacamos las palabras de La Publicidad, recogidas también en la comunicación de Ardolino:

Arthur Cravan, llamado no sabemos por qué, campeón de Europa, semejaba la zorra huyendo del león. Los brazos de Johnson son una catapulta que al descargar sus martillazos sobre el cuerpo del pobre Cravan lo enrojecían hasta convertirlo en un deslavazado cuerpo humano sanguinolento. Un vaho de sudor y de congoja emanaba del ring.

Hacemos gracia a nuestros lectores de los detalles del match de ayer. Primero porque somos enemigos acérrimos de esta nueva brutalidad que de arraigar en nuestra patria, de bracete con los toros, nos dejaría apañados; y segundo porque fue tan insulso y la comedia tan ignominiosa, que si no fuera 
por hacer constar nuestra más enérgica propuesta nada diríamos (Cit. en Ardolino 372).

En esta línea se pronuncia también el reportero deportivo que el día siguiente escribe un artículo «advocant perquè en endavant no poguessin ésser tolerades semblants salvatjades, pròpies - deia innocentment- d'un país autènticament inculte» (Trabal, Quo vadis 53), ${ }^{2}$ un apunte que Sànchez parece olvidar, entestado solamente en corresponder el deseo de Isabel, totalmente ficcional. Por otra parte, Ardolino ha querido ver una relación del absurdo de las preguntas y respuestas del formulario que Sànchez rellena en la Oficina del Servicio de Orientación Profesional con las del curso de topografía que presentaba el narrador de La vida trafegosa (1919) de Bontempelli, a pesar de que, más adelante, lo asocia a una «fortuïta coincidència» (Ardolino376), si tenemos en cuenta -y nos tomamos seriamente- las palabras que Trabal dirige en una carta a Joan Triadú el 8 de junio de 1949, donde confiesa que «no he llegit mai una ratlla de Bontempelli» (Triadú 57). Sin embargo, recuperamos el acierto de la relación propuesta por Ardolino, porque permite entender mejor el retrato de Sànchez como el de un hombre confuso, perdido y absorto de la realidad que vive.

Así, Sànchez, bandeado de la sociedad, se convierte en un personaje-tipo ridiculizado continuamente en los diferentes intentos por asumir un rol social que no le corresponde. Por eso, los socios del club de natación, considerándolo «un de més a la colla de titelles» (Trabal, Quo vadis 102), más allá de ser considerado por los socios como parte del grupo, lo elevan

al capdamunt de la troupe de gallofes. Faceciosament, com si ja l'esperessin, uns quants recòrdmen se l'emprengueren pel seu compte i per començar li abocaren una ampolla d'aigua oxigenada als cabells, simulant una fricció de Pompeia: en Sànchez, en arribar aquell vespre a casa seva, quedà desmaiat en un sofà, de veure's dins el mirall amb els cabells daurats com un fil d'or (Trabal,Quo vadis 102-103).

Una situación que se acentuará todavía más cuando pasa a formar parte del equipo de waterpolistas del CN Barcelona, que lo consideran una marioneta y le desgarran el bañador «i l'abandonaren tot un a la multitud i a l'espant de tots els esbarts de donzelles

\footnotetext{
${ }^{2}$ La cursiva es del autor.
} 
que fugiren horroritzades» (Trabal, Quo vadis 103). Nuevamente, el desequilibrio se establece entre nuestro protagonista y una entidad colectiva con la que no parece encajar. El problema de Sànchez es, pues, también el del papel de «mingo» que cumple «entre el seus camarades» (Trabal, Quo vadis 103), motivo por el que sus aspiraciones deportivas fracasan sucesivamente. Como apunta Iribarren (298), el Sànchez trabaliano, «és, essencialment, un somniador» porque, en efecto, intenta «evadir-se de la pròpia grisor personal i de la mesquinesa de les seves circumstàncies vitals», un hecho que explica, en parte, la tendencia del protagonista a intentar transfigurar la realidad de acuerdo con su deseo. De hecho, como nos hace ver el narrador, el Sànchez de Trabal es alguien con una consideración vital más bien baja, de pretensiones mínimas o nulas:

Les il·lusions d'en Sànchez sempre havien estat planes, mai haurien pogut amidar-se cúbicament. Des del posar-se els dits al nas, passant pel saltar i parar, i pel descobriment dels gaudis cinematogràfics i el mirar les publicacions amb imatges de cinema, fins arribar a l'èxtasi espiritual de clavar una puntada de peu a una pilota de futbol, totes les seves il.lusions obeïen les mateixes directives: descobertes, gairebé invencions, al voltant de les quals, com satèl·lits passatgers, de vegades brillaven esquitxos d'idees, l'abast de les cuals per en Sànchez havia estat absoluntament indesxifrable (Trabal, Quo vadis 66-67).

Por eso, el narrador nos confiesa que la aparición del deporte en la vida de Sànchez desembocará en una búsqueda desesperada por encontrar el adecuado a su forma de ser que nace a partir de una sentencia de un conferenciante: «...Tots hem nascut per a un esport o altre! Es tracta només que cadascú trobi el seu esport» (Trabal, Quo vadis 70), razón por la que, además, la entrada en el club de tenis se convierte en «la primera sensació forta de la seva vida» (Trabal, Quo vadis 67), como un intento de construcción de su identidad:

Amb tota la seva vida anterior al damunt -com una motxilla ridícula a l'esquena- entrà al tennis sense saber què li esperava, sense sospitar-ho. I així que arribà a les envistes de les pistes de joc hagué d'aturar-se: les evolucions suaus d'uns esbarts que cregué immaterials, talment habitants d'un altre planeta, l'obligaren a deixar a terra la càrrega que duia, i bocadabat no es recordà més de la motxilla i l'oblidà arran d'un parterre de peònides florides, que es desfullaren embascades d'aquell contacte... (Trabal, Quo vadis 67) 
La imagen, de una fuerte carga metafórica, es también símbolo evidente de la vulgaridad que persigue la identidad sanchista de Trabal y, más todavía, parece predecir la dirección que tomará esta nueva experiencia, porque el protagonista fracasará, al menos inicialmente, en el intento de asumir un rol propiamente deportivo y «l'aproximar-se a aquelles noves esferes no féu néixer en la seva ambició sinó un enfavament autèntic, un contentisme embascador, una mena de peix en aigua de roses» (Trabal, Quo vadis 67). El fracaso de Sànchez se produce, pues, por la consciencia de la propia mediocridad, razón que imposibilita que nuestro protagonista pueda experimentar un proceso de identificación que permita la huida de lo que parece ser el destino de cualquier Sànchez. Por eso, el narrador nos advierte:

D'altres Sànchez, pastats amb la mateixa pasta, corren prou abundosament entre nosaltres: però un fet casual els haurà situat més aviat que al nostre home, i això els fa passar més desapercebuts a la turbamulta. ¿Quants Sànchez trobaríem sota l'aurèola inexplicable d'un excel·lent comptable, d'un famós general, d'un popular futbolista, d'un repòrter de moda, d'un metge il·lustre, d'un dramaturg sensacional...? (Trabal, Quo vadis 67-68)

Si nos fijamos bien, el narrador no duda en hacernos ver el relato de la vida de Sànchez desde esta mirada vulgar e indiferente, por el mismo hecho de que «en Sànchez, el nostre Sànchez no sabia o no podia arribar a trobar-se» (Trabal, Quo vadis 68). El Sànchez de Trabal se define también desde esta perspectiva de hombre-tipo, cuyo carácter determina el destino de muchos hombres y deja poco espacio a la imaginación, a la huida transcendente: «¿Qui pot bastir castells de supòsits en la vida de tots els Sànchez? // De tots ells, si som capaços d'intentar-los, ¿no n’és un dels més lògics el camí que en realitat el nostre Sànchez prengué? És a dir, prengué, ¿seguí?» (Trabal, Quo vadis 69)

Llegados a este punto, la aparición del automovilismo en la vida de Sànchez se plantea como una desgracia en términos absolutos: nuevamente, se deja llevar por el consejo equívoco de otro y, conductor inexperto, atropella a un ciclista y lo mata. La consecuencia directa de este hecho es la cárcel, un espacio aislado para la sociedad que lo margina constantemente, pero no para él, que lo interpretará como una oportunidad para verse tal como es, sin ningún tipo de presión social. Un hecho que, además, coincidirá con 
la aparición del juego de la trompa, una antítesis del deporte físico y, a la vez, el punto de partida del éxito y el reconocimiento de Sànchez, primero en la cárcel y más tarde como ganador del campeonato mundial en Colonia, y también por la relación amorosa que inicia con su futura esposa, Genoveva, símbolo de la felicidad doméstica. Como apunta Teresa Iribarren (323): «En la seva figura [la de Sànchez] s’objectualitza aquest permanent desencaixament, que el converteix en l'antiheroi per antonomàsia: és víctima d'amputacions, agressions físiques diverses, humiliacions constants, abusos i càstigs». La salvación, sin embargo, llegará con la renuncia de este "éxito" y del dinero para volver a la vida anónima y vulgar. El Sànchez trabaliano se salva, en efecto, cuando decide «espolsarse tota la vida fantasista de sobre» (Trabal, Quo vadis 154), es decir, cuando adapta su vida a los horizontes que tiene marcados como pequeño burgués y sigue los patrones establecidos de la familia tradicional. Por eso, elimina «tot allò que havia originat els seus trasbalsos i els seus sotracs» y «proposà a la seva muller d'encarregar a Colònia, perquè arribes a petite vitesse, un gamarrusset que els animés l'existència i els assegurés la vellesa millor que no pas aquells bitllets de mil, culpables de tants embulls» (Trabal, Quo vadis 154). Al fin y al cabo, Sànchez no consigue la felicidad que buscaba con la exploración del deporte ideal, como aseguraba el conferenciante, sino en la asimilación de los elementos genuinos de la vida doméstica. Tanto es así que nuestro protagonista, cuando muere, lo hace con dos elementos ajenos a su cultura, con los que, en cambio, parece comulgar ahora: una «guitarra»y «unes penjarelles de tomàtecs» (Trabal, Quo vadis 155). Así, el Sànchez trabaliano se convierte ciertamente en un «exemple d'humanitat digne de no oblidar» (Trabal, Quo vadis 153), precisamente porque asume el destino que tenía asignado como hombre-tipo, de manera que la desaparición del Sànchez trabaliano con la que se cierra la novela es fruto de aceptación de esta premisa y no lo convierte en un héroe sino más bien en alguien que consigue ser feliz entre la colectividad.

\section{Conclusiones}

Quo vadis, Sànchez? se plantea como una parodia de la novela deportiva, sobre todo en la medida que pone de manifiesto las carencias de una sociedad deslumbrada por el deporte, un fenómeno que, como el cine, la electricidad, la velocidad o la prensa, es considerado un símbolo de modernidad y de heroicidad. Al fin y al cabo, el Sànchez de 
Trabal intenta encontrar «la jeia», «el seu jaç» dentro de una vida prefabricada, diseñada de antemano cuyas modificaciones parecen casi imposibles, por su condición de Sànchez, esto es, de nadie: «¿Què sabia ell de la seva vida, si no podia veure-la? La seva única línia recta era l'esport. I si no passava per damunt aquesta línia recta -grotesca maroma de fil d'empalomar-, si no vivia entre l'esport, ¿què faria? ¿Què podria fer? Ell no coneixia res més d'aquest món» (Trabal, Quo vadis 70). Quo vadis, Sànchez? escapa de la simple consideración del absurdo y, por el contrario, se trata de una propuesta con un carácter mucho más intelectual y crítico que afecta directamente a la sociedad moderna a la que evoca y se refiere constantemente, simbolizada en el prototipo del protagonista. Al fin y al cabo, en la angustia de Sànchez se ve representado el desencaje permanente entre la realidad que lo envuelve y el mundo irreal en el que imagina (y pretende) vivir. La actitud desorientada de Sànchez responde en realidad a un conjunto de estrategias predefinidas que la tradición literaria (y también la cinematográfica) ha consolidado a través de una sucesión repetida de eventos que Trabal proyecta en su personaje precisamente para subvertir el esquema-tipo y transformarlo. El conjunto de acciones que se desencadenan dentro de Quo vadis, Sànchez? y, sobre todo, la perspectiva desde la que Sànchez las "asume" hacen ver la novela como un ejemplo de obra que aborda el conflicto de identidad del individuo en el mundo contemporáneo, un aspecto que, además, pone en contacto a Trabal con las tendencias vanguardistas europeas. Así pues, la novela se plantea como una búsqueda del conocimiento desde un cuestionamiento de la vida aparente, de la realidad aparente; a través de la experiencia sanchista, Trabal establece una crítica de la verdadera realidad oculta bajo la aparente prosperidad de la sociedad avanzada del momento, representada en la cultura deportiva. Más allá de esta realidad aparente, Sànchez es, irónicamente, un hombre sin rumbo, alguien que, incansablemente (y, sin embargo, sin éxito), no hace nada más que buscarse a sí mismo. 


\section{Bibliografía}

Ardolino, Francesco."Francesc Trabal o la ironia del joc". La ironia en les literatures occidentals des de l'inici de segle fins a 1939. Eds. Ferran Carbó, Carme Gregori Soldevila y Ramon Xavier Rosselló. Barcelona: Publicacions de l'Abadia de Montserrat, 2016. 363-384.

Arnau, Carme. "Francesc Trabal o l'erotisme", Marginats i integrats en la novel-la catalana (1925-1938). Introducció a la novel-lística de Llor, Arbó, Soldevila i Trabal. Barcelona: Edicions 1987. 117-157.

Bach, Miquel."Francesc Trabal, un humor impossible" De cara a la paret. Francesc Trabal. Sabadell: Ajuntament de Babadell, 1985. 13-32.

Bach, Miquel. "El 'Coro' de Santa Rita, altrament anomenat Grup de Sabadell (I)". Arraona 9 (1991): 67-80.

Balaguer, Josep M. "Francesc Trabal i la paròdia de la novel·la". De Rusiñol a Monzó: humor i literatura. Eds. Margarida Casacuberta y Marina Gustà. Barcelona: Publicacions de l'Abadia de Montserrat, 1996. 67-87.

Banyeta, Sr. "Amb això del Terrassa-Sabadell, sembla que ens els prenguin”. Diari de Sabadell 1.629 (24-6-1925).

Dasca, Maria “La inventiva de la invectiva. L'amour fou de Judita”. Revista de Catalunya 206 (2005): 61-72.

Genette, Gérard. Palimpsestes. La littérature au second degré. París: Seuil. 1992

Guansé, Domènec. "L'humor i l'esport. El 1libre de Trabal”. La Rambla. 7 (1931): 7.

Guerau de Liost. Sàtires. Barcelona: Quaderns Crema, 1999

Hutcheon, Linda. A Theory of Parody. The Teachings of Twentieth-Century Art Forms. New York-London: Methuen, 1985

Iribarren, Teresa. Literatura catalana i cinema mut. Barcelona: Publicacions de l'Abadia de Montserrat, 2012

Martí-Olivella, Jaume. "Trabal i Calders, o la incorporació distorsionada del fantàstic". Actes del Quart Col-loqui d'Estudis Catalans a Nord-Amèrica. Estudis en honor d'Antoni M. Badia i Margarit. Eds. Josep Massot i Muntaner, Nathaniel Smith, Josep Solà-Solé y Mercè Vidal Tibbits. Barcelona: Publicacions de l'Abadia de Montserrat, 1985. 277-293.

Marrugat, Jordi. “Creació crítica, crítica creativa: 1'agitació cultural del Grup de Sabadell als anys 1924-1928”. Estudis romànics 39 (2017):225-251. http://publicacions.iec.cat/repository/pdf/00000243/00000020.pdf.

Mirador ."indiscret". Mirador: setmanari de literatura, art i política 97 (1930): 1.

Montoliu, Manuel de. "Francesc Trabal. Quo vadis, Sànchez? La Rambla. La Veu de Catalunya (1932): 5.

Oliver, Joan. Francesc Trabal, recordat, Sabadell: Fundació La Mirada, 1999.

Oller, Dolors. "Pròleg Francesc Trabal “Judita. Barcelona: Edicions, 62. 1977. 5-19.

Pessarrodona, Marta. Mercè Rodoreda i el seu temps. Barcelona: La Rosa dels Vents, 2005.

Pinell, Jordi. Francesc Trabal i les seves novel-les. Roma: Dipartimento di Studi Romanzi, 1983.

Poch, Anna. "L'esport en l'obra de Francesc Trabal: entre la denúncia i la modernitat". Arraona 29 (2005): 60-69.

Porta, Roser. Mercè Rodoreda i l'humor (1931-1936): les primeres novel-les, el periodisme 
$i$ Polèmica. Barcelona: Fundació Mercè Rodoreda, 2007.

Rodoreda, Mercè. Crim, Barcelona: La Rosa dels Vents, 1936

Rose, Margaret A. Parody: Ancient, Modern, and Post-modern. Cambridge: Cambridge University Press, 2000

Rosselló i Bover, Pere. "Entorn de Francesc Trabal i la modernització de la novel·la catalana". Revista de Catalunya 33 (1989): 127-139.

Sangsue, Daniel. La parodie. París: Hachette, 1994.

Simbor, Vicent. "Francesc Trabal: 1'aposta pel narrador revoltat". Zeitschrift für Katalanistik 26 (2013): 249-274.

Trabal, Francesc. "La venjança dels 'Alumnes de Viladecavalls P.T.” La Rambla de Catalunya 4 (1928).

Trabal, Francesc. Quo vadis, Sànchez?. Barcelona: Quaderns Crema, 1988.

Triadú, Joan. "Una carta de l'exili de Francesc Trabal”. Serra d'Or 262. 263 (1981): 57-58. 